\title{
Clinical Factors Associated with Intestinal Strangulating Obstruction and Recurrence in Adhesive Small Bowel Obstruction
}

\author{
MOHAMED IBRAHIM SHALAMESH, M.D. \\ The Department of General Surgery, General Faculty of Medicine (Boys), Al-Azhar University
}

\begin{abstract}
Background: Post-operative adhesions are a mutualreason of small-bowel obstructions, and up to 53 percent of cases operated on for adhesive small-bowel obstructions (ASBO) face recurrences. Our study evaluated the clinical parameters accompanied with strangulating obstructions and the risk factors with ASBO rate of recurrence.
\end{abstract}

Patients and Methods: A retrospective research has been carried out by the department data-base. 80 Patients with ASBO were included in the study and followed-up from January 2016 to July 2018 at Sayed Galal University Hospital. The clinical issues a companied with strangulation of obstructions and recurrences after ward treating were assessed.

Results: Of the 80 involved ASBO cases, the obstructions recurred in 22 patients with a rate of recurrence was $27.5 \%$ $(22 / 288)$, and 6 of those 22-patients experienced repeated surgical operation [rate of re-operation $27.3 \%(6 / 22)$ ], whereas the other 16 cases underwent conservation treatment. The rate of recurrent of the simple ASBO group was $28.6 \%$ (19/72), and the median non-recurrence period was $12.2-\mathrm{mths}$. The rate of recurrence of the strangulating obstructing group was $37.5 \%(3 / 8)$, and the median non-recurrence period was 11.5mths. The alterations among the studied groups were considered as non-significant ( $p$-value $=0.241)$.

Conclusion: Four clinical factors involving leukocytosis, tachycardia, together with CT results of thickening or swelling of the mesentery and CT displaying seroperitoneum, a companying with incidence of intestinal strangulations in ASBO. ASBO-cases who experienced operative intervention had a decreased rate of recurrence, but ASBO-cases with strangulating obstructions hadn'trise therate of recurrence in comparison to those of cases with simple ASBO.

Key Words: Adhesive small bowel obstruction - Clinical parameter - Following-up - Intestinal strangulation-Recurrence.

\section{Introduction}

ADHESIVE small bowel obstruction (ASBO) is one of the mainreasons of operative emergency

Correspondence to: Dr. Mohamed Ibrahim Shalamesh, The Department of General Surgery, General Faculty of Medicine (Boys), Al-Azhar University and in specific of operative emergency that need emergent procedures [1] in one review of 87 studies involving 11007-cases, the occurrence of ASBO succeeding all kinds of abdominal surgeries was $2.4 \%[2]$.

The incidence of recurrent ASBO rises with the extent of following-up reaching 16-53\%. An elevated number of preceding ASBO events, conventional interventions, ages $<40$-yrs, matted adhesion, and Post-operative complications rise the recurrence risk [3]

Symptoms of compromised perfusions of the small-intestinein volving nonstop abdominal pains, leukocytosis, fever, and tachycardia, symptoms of peritoneal irritations, hyperamylasemia, and metabolic acidosis aren't dependable for diagnosis intestinal ischemia or comprehensive bowel obstructions [4].

ASBO leads to significant harm, resultant in 8-days of hospital-stay on average and an inhospital death rate of 3\% for every episode [5] About 20 upto $30 \%$ of cases with ASBO need surgical interventions [6]

The principal reason of ASBO scure failure isbecause of delayed diagnosing and operative intervention for strangulating obstruction. Controversy still as to which ASBO-cases want fast surgical operation; therefore, how to differentiate strangulating obstructions from a simple ASBO is very significant [7].

While ASBO is a shared disorder, the preventions and treatments are often defined by surgeons' ownfavors instead of standard evident-built procedures [8].

Surgeons must know that the adhesions leading to bowel obstructions are characteristically the footprints of preceding abdominal operations or 
disorders. Part of the adhesions creation could be avoided by using of minimal invasive surgeries and the utilization of adhesion barrier [9]. The majority of ASBO-cases could be managed nonsurgically. If surgical intervention is needed, a laparoscopic methodmay be advantageous for simple situations [10].

Operation for small-intestine obstructions is accompanying with a death of up to 10 percent. Also, adhesions are recognized to lead to chronic painson abdomen and are existing in up to $57 \%$ of cases with post-operative chronic pains [11].

The present work is aimed to evaluatethe clinical factors associated with strangulating obstructions and the risk factors with ASBO rate of recurrence.

\section{Patients and Methods}

This retrospective study done in Sayed Galal University Hospital was conducted on 80 cases of SBO from January 2016 to July 2018 by using the department database.

Inclusion criteria for ASBO must be satisfy one of the next situations: Plain abdominal radiographs or abdominal US giving confident multi air-fluids levels in the small-intestine but no sign of gas within the colon; CT or MRI examinations displaying small intestine obstructions; approval of ASBO by laparo-tomy or laparo-scopy.

Exclusion criteria were abdominal obstructions secondary to colon tumor, small intestine carcinoma, gastro-intestinal stromal tumor (GIST), or metastatic tumor; past of intra-abdominal thermotherapy or radio-therapy; obstructions made by stool masses; intestinal tuberculosis; and early post-operative obstruction in 1-mth.

Informed written consent was obtained from each patient to be included in the current work.

Primary assessment for ASBO-cases was as next: Past of abdominal operation; presenting signs of abdominal pains and distension, vomiting, nausea, or a absence of flatus and defecations; physical examinations viewing abdominal swelling with intestines with palpable peristaltic waves, tenderness, alteringintestine sound, or peritonitis.

Clinical factors collecting comprised the next: General state: Gender, ages, past of surgical operation \& abdomen trauma; symptoms \& physical signs: Fever, growing heart rates, continued abdominal pains, weakening or dis-appearing intestine sound, and peritoneal inflammation.
Laboratory examination: Peripheral blood white blood cell counts and aspartate aminotransferase (AST) value; imaging examinations: CT results of lessening intestine wall densities and thickening or swelling of the mesentery, and abdomen space effusions (seroperitoneum).

Signs for operative treatment were built on close monitoring of the clinical signs, lab. testing, and serial radiologic results. The concluding choice to go to surgical operation was made by surgeons. To assess the prediction of ASBO cases, followingup was showed by the doctors who manage the cases.

The medical data, involving symptoms, lab. tests, and imaging examination, were studied.

\section{Results}

Of these 80 cases, there were 44 -male $(55 \%)$ and 36-female (45\%) with age rangebetween 19 and 71-yrs, the ages median was 51-yrs (39 to 61yrs) and ages average of $51.3 \pm 14.2$-yrs. The following-up of these 80-patients continued from Jan 2016 to July 2018 with no any mortality. The most extended following-upperiod continued for 16mths, and the least periodcontinued for 6-mths. The entire median nonrecurrence period was 11.8mths. In this work, 38-cases $(47.5 \%, 38 / 80)$ experienced a surgery. Of these, 26-cases experience denterolysis, and the other 12-cases experienced small intestine resection $\&$ anastomosis. 42 -cases $(52.5 \%, 42 / 80)$ experienced conservative management. Eventually, 8-patients were detected as ASBO with strangulating obstructions, and 72-patients were detected as simple ASBO (Table 1).

Table (1): Demographic and clinical data of the studied groups.

\begin{tabular}{|c|c|c|c|}
\hline Demographic data & $\begin{array}{l}\text { Strangulation } \\
\text { group } \\
(\mathrm{n}=8)\end{array}$ & $\begin{array}{l}\text { Simple } \\
\text { group } \\
(\mathrm{n}=72)\end{array}$ & $\begin{array}{c}p- \\
\text { value }\end{array}$ \\
\hline \multicolumn{4}{|l|}{ Age /-yrs: } \\
\hline $\begin{array}{l}\text { Mean } \pm \text { SD } \\
\text { Range }\end{array}$ & $\begin{array}{l}50.1 \pm 7.3 \\
(39-55)\end{array}$ & $\begin{array}{l}53.8 \pm 7.3 \\
(44-61)\end{array}$ & $0.224^{1}$ \\
\hline \multicolumn{4}{|l|}{ Sex: } \\
\hline Male & $5(62.5 \%)$ & $39(54.2 \%)$ & $0.372^{2}$ \\
\hline Female & $3(37.5 \%)$ & $33(45.8 \%)$ & \\
\hline History of trauma & $2(25 \%)$ & $21(29.2 \%)$ & $0.514^{2}$ \\
\hline History of surgery & $6(75 \%)$ & $61(84.7 \%)$ & $0.091^{2}$ \\
\hline $\begin{array}{l}\text { Persistent abdominal } \\
\text { pain }>48 \text { hours }\end{array}$ & $6(75 \%)$ & $33(45.8 \%)$ & $<0.001 * 2$ \\
\hline Temperature $>37.5^{\circ} \mathrm{C}$ & $1(12.5 \%)$ & $11(15.3 \%)$ & $0.028 * 2$ \\
\hline Tachycardia >100PPM & $4(50 \%)$ & $9(12.5 \%)$ & $0.004 *^{2}$ \\
\hline $\begin{array}{l}\text { Bowel sound weakening } \\
<3 \text { minutes }\end{array}$ & g $6(75 \%)$ & $36(50 \%)$ & $<0.001 * 2$ \\
\hline Peritonitis & $5(62.5 \%)$ & $11(15.3 \%)$ & $<0.001 * 2$ \\
\hline
\end{tabular}


In Table (2), strangulation group had higher mean of WBCs than simple group with statistical significant difference. Also, CT results as reducing intestine wall densities, Thickening or swelling of mesenteric and Seropertonium were significantly higher among strangulation group than simple group (Fig. 1).

Table (2): Investigations data of the studied groups.

\begin{tabular}{lccc}
\hline & $\begin{array}{c}\text { Strangulation } \\
\text { group } \\
(\mathrm{n}=8)\end{array}$ & $\begin{array}{c}\text { Simple } \\
\text { group } \\
(\mathrm{n}=72)\end{array}$ & $\begin{array}{c}p \text { - } \\
\text { value }\end{array}$ \\
\hline $\begin{array}{l}\text { WBCs count }\left(* 10^{9} / \mathrm{L}\right) \\
\text { AST (U/L) }\end{array}$ & $16.3 \pm 1.8$ & $11.8 \pm 2.2$ & $<0.001 * 1$ \\
$\begin{array}{l}\text { CT findings: } \\
\text { - Decreasing intestinal } \\
\text { wall density }\end{array}$ & $5(62.5 \%)$ & $33(45.8 \%)$ & $0.01 *^{2}$ \\
$=\begin{array}{l}\text { Thickening or swelling } 7(87.5 \%) \\
\text { of mesenteric }\end{array}$ & $35(48.6 \%)$ & $<0.001 * 2$ \\
- Seropertonium & $7(87.5 \%)$ & $35(48.6 \%)$ & $<0.001 * 2$ \\
\hline
\end{tabular}

WBCs: White blood cells.

AST : Aspartate aminotransferase.
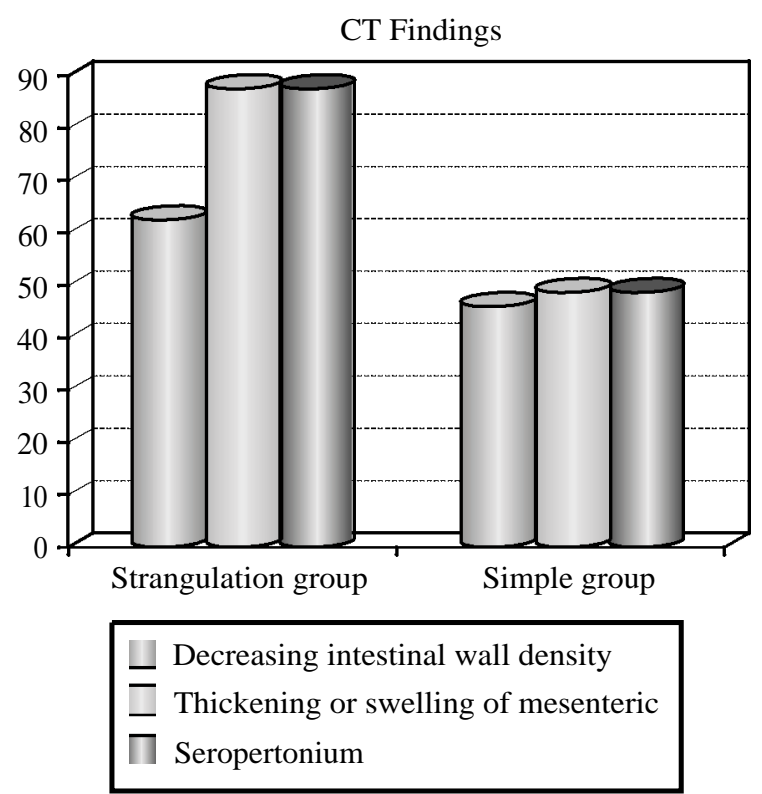

Fig. (1): CT findings in both groups.

The clinical features a companying with strangulating obstructions of the 288-patients involve the next: Rising heart rates (>100bpm), rising WBC counts $(>15 \times 10 / \mathrm{L})$, CT results of mesentery thickening or swelling, and CT display seroperitoneum. These clinical factors were accompanying with elevated intestinal strangulation risk $(p$-value <.05) (Table 3).
Table (3): Multiple logistic regression analysis to predict factors.

\begin{tabular}{|c|c|c|}
\hline & OR $95 \% \mathrm{CI}$ & $\begin{array}{c}p- \\
\text { value }\end{array}$ \\
\hline $\begin{array}{l}\text { Persistent abdominal pain } \\
>48 \text { hours }\end{array}$ & $1.62(0.98-2.11)$ & 0.152 \\
\hline Temperature $>37.5^{\circ} \mathrm{C}$ & $1.11(0.65-2.3)$ & 0.423 \\
\hline Tachycardia $>100 \mathrm{PPM}$ & $5.8(3.8-17.3)$ & $0.011 *$ \\
\hline $\begin{array}{l}\text { Bowel sound weakening } \\
<3 \text { minutes }\end{array}$ & $1.87(0.88-3.21)$ & 0.219 \\
\hline Peritonitis & $1.33(0.78-2.18)$ & 0.110 \\
\hline WBCs count $\left(* 10^{9} / \mathrm{L}\right)$ & $9.2(4-18)$ & $0.021 *$ \\
\hline $\begin{array}{l}\text { Decreasing intestinal wall } \\
\text { density }\end{array}$ & $1.23(0.98-1.87)$ & 0.082 \\
\hline $\begin{array}{l}\text { Thickening or swelling of } \\
\text { mesenteric }\end{array}$ & $12.3(3-35)$ & $<0.001 *$ \\
\hline Seropertonium & $13.9(2-41)$ & $<0.001 *$ \\
\hline
\end{tabular}

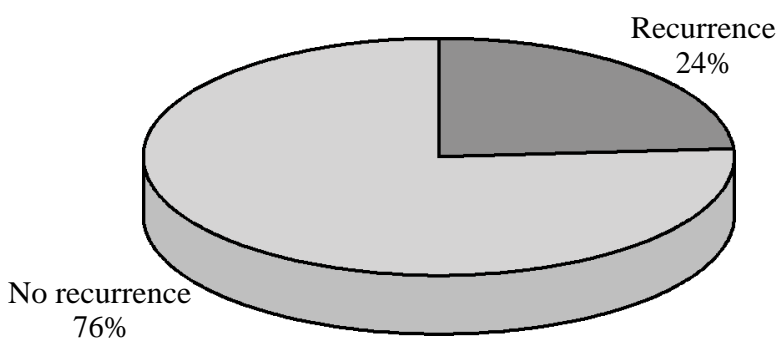

Fig. (2): Recurrence rate among the study patients.

In Table (4), among the 80 involved ASB-cases, the obstructions recurred in 22-patients with a rate of recurrence of $27.5 \%(22 / 288)$, and 6 of those 22 -cases experienced repeated surgical operation [rate of re-operation was $27.3 \%(6 / 22)$ ], whereas the other 16 cases underwent conservation treatment. Therate of recurrent of the simple ASBOgroup was $28.6 \%$ (19/72), and the median nonrecurrence period was 12.2 -mths. The rate of recurrence of the strangulating obstructions-group was $37.5 \%$ (3/8), and the median non-recurrence period was 11.5 -mths. The changes among these study groups weren't counted as significant ( $p$ value $=0.241)$.

Table (4): Recurrence after surgery or conservative management.

\begin{tabular}{llll}
\hline & $\begin{array}{c}\text { Strangulation } \\
\text { group (n=8) }\end{array}$ & $\begin{array}{c}\text { Simple } \\
\text { group (n=72) }\end{array}$ & $\begin{array}{c}p \text { - } \\
\text { value }\end{array}$ \\
\hline Recurrence & $3(37.5 \%)$ & $19(26.4 \%)$ & $0.385^{1}$ \\
$\begin{array}{l}\text { Median non-recurrence } \\
\text { interval (months) }\end{array}$ & 11.5 & 12.2 & 0.2412 \\
\hline
\end{tabular}




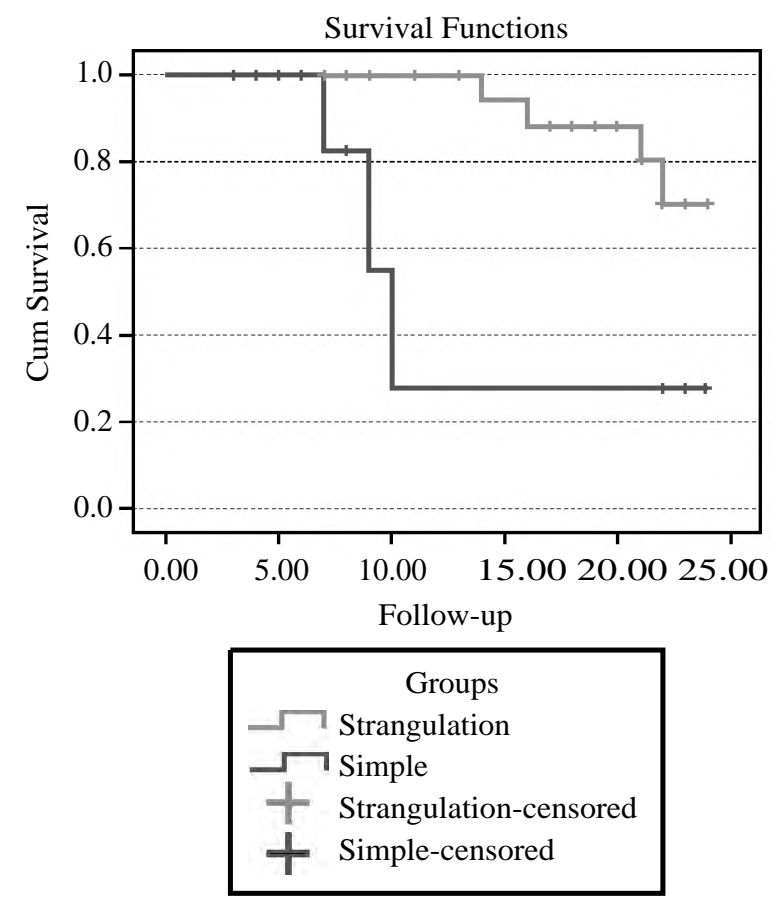

Fig. (3): Rates of recurrence comparing among various intestine obstruction kinds.

\section{Discussion}

Intestinal obstruction is one of the commonest abdominal emergencies and has a complex pathogenesis and varying prognosis; mortality could be the most critical consequence. Commonly, ASBOproduced by Post-operative adhesions, and ASBOs are accountable for $60 \%$ to $75 \%$ of small intestine obstruction [12]

It was reported that intra-peritoneal adhesions happened in 50 up to $100 \%$ of cases who experience abdomen surgeries. Post-operative adhesion is a major health issue with main consequences on quality of life (QoL) and health care costs. ASBO was the commonest kind of obstructions and is associated with an elevated rate of abdomen reoperation [13]

Adhesions can lead to incidents of acute abdomen because of intestine strangulations, consequently, expecting the requirement for operative treatment between ASBO-cases is a challenge. The diagnosing of intestine strangulation is very significant for cases to accomplish better consequence streatments [14].

Adhesive Intestine obstruction is an unavoidable complicating of abdomen operations with substantial morbidities accompanying with poor QoL and incline to repetitive hospital-stay. The majority of them (73\%-90\%) could be conservatively treated. In spite of developments in surgeries, 15 to $30 \%$ need operative treatment mainly or because of failureson conservative treatment. Owing to the nature of the disorder recurrences were calculated to be $30 \%$ [15].

In this study we aimed to evaluate the clinical factors accompanying with strangulating obstructions and the risk factors with ASBO recurrence rate.

This was a retrospective study, was conducted on 80 patients matched the inclusion criteria, of these 80 -cases, there were 44-male (55\%) and 36female $(45 \%)$ with age range between 19 and 71 yrs, with ages median of 51-yrs (39 to 61-yrs) and ages average 51.3 \pm 14.2 -yrs. The following-up of these 80-patients continued from January 2016 to July 2018 with no any mortality. The most extended following-up period continued for 16-mths, and the least period was 6-mths. The entire median nonrecurrence interval was 11.8 -mths. In this work, 38 -cases $(47.5 \%, 38 / 80)$ experienced a surgery. Of these, 26-cases experience denterolysis, and the other 12-cases experienced small intestine resections and anastomosis. Forty-two patients $(52.5 \%$, 42/80) conservatively managed. Finally, 8-patients were detected as ASBO with strangulating obstructions, and 72-case were identified as simple ASBO.

In agreement with our findings, the study of Mu et al., [16] was conducted on 288-cases, there were 151-men (52.4\%) and 137-women (47.6\%) with age range between 14 and 97-yrs, with ages median of 54-yrs (45 to 66-yrs) and ages average of 54.8 \pm 15.4 -yrs. The following-up of these 288cases continued from Sep-2013 to Apr-2016 with no mortality. The most extended following-upperiod continued for 37-mths, and the least intervalwas 6-mths. The overall median nonrecurrence interval was 32.2-mths. In this work, 122-cases $(42.3 \%$, 122/288) experienced surgeries. Of these, 83 -cases experience denterolysis, and the other 39-cases experienced small intestine resections and anastomosis. 166-cases $(57.6 \%, 166 / 288)$ conservatively managed. Eventually, 37-patients have been identified as ASBO with strangulating obstructions, and 251-patients were identified as simple ASBO.

In the study of Kabbash et al., [17] Age of the study participants ranged from 25-77-yrs with mean of 49.4-yrs and the majority of patients 32 (66\%) were between 30-60-yrs. Also, most of the study participants were females (60\%) with male to female ratio 1:1.5, All of our study subjects had previous abdominal surgery 50 patients (100\%), distributed as follow appendectomy 16 patients (32\%), followed by Cesarean section 12 patients 
(24\%), then cholecystectomy 11 patients (22\%), then exploration 9 patients $(18 \%)$ and lastly splenectomy 2 patients (4\%).

Intestinal strangulating is accompanying with intestine necrosis and severe intra-peritoneal infections; consequently, timely identification of intestine strangulations when there is sign of an acute abdominal is essential for operative deciding. Our work displays that tachycardia and leukocytosis highly accompanied with incidence of intestine strangulations in ASBO. The clinical features accompanying with strangulating obstructions of the 288-patients involve the next: Rising heart rates (> 100bpm), elevating WBC counts (> 15x $\left.10^{9} / \mathrm{L}\right)$, CT results of mesentery swelling or thickening, and CT viewing seroperitoneum. These clinical factors were accompanying with raised intestine strangulation risk $(p<.05)$, the results are constant with preceding reports of Strik et al., [3] and Di Saverio et al., [8]

Notably, current study is similar to Williams et al., [18] contrarily, we list some clinical features for intestine strangulations in ASBO cases, involving fever, heart rates, and abdomen pains. Tachycardia, Fever, and leukocytosis were classical signs of ASBO. Thus, they have been taken in consideration as accompanying clinical features for intestine strangulation sinstead of as risk factors participate to abdomen adhesions. The classical symptoms mirror the abdominal infections everity; but, the consequences from standard clinical tests frequently absence details and precise data specific to intestine strangulations.

In the current study, Also CT results as reducing intestine wall densities, swelling or Thickening of mesenteric and Seropertonium were significantly higher among strangulation group than simple group.

Similar to our findings, the study of Bouassida et al., [19] reported that multi-CT scans results were much more mutual in cases with Intestine ischaemia, involving ascites, thick-walled small intestine, segmental mesenteric fluids and decreased wall enhancements.

$\mathrm{Mu}$ et al., [16] concluded that CT results of swelling or thickening of mesentery, and CT display seroperitoneum highly accompanying with intestine strangulations.

It was concluded by Matsushima et al., [20] that $\mathrm{CT}$ is a valued imaging method for detecting the reason of intestine obstructions and for definingif an intestine hemodynamic disorder presents or not.
To precisely expect intestine strangulations in ASBO cases, surgeons must associate clinical symptoms, lab. examinations and imaging results.

ASBO needs suitable treatment with a proper diagnosing and therapy path-ways. Sign and length of non-operative management and proper timing for operation can be an insidious subject. Postponement in operative treatment scanlead to a consider ablerises of morbidities and mortalities [17].

In the current study, of the 80 involved ASBO cases, the obstruction sreappeared in 22 patients with arate of recurrence of $27.5 \%(22 / 288)$, and 6 of those 22-cases experienced repeated surgeries [rate of re-operation $27.3 \%(6 / 22)$ ], while the other 16-patients experienced conservational management.

Lorentzen et al., [21] concluded that the total rate of recurrence after ward operatively managed ASBO was $12.1 \%$, and there currence risk factors were females, multi/matted adhesion, and fascial dehiscence.

We are in a harmony with the study of Mu et al., [16] in which the obstructions recurred in 84patients with arate of recurrence of $29.2 \%$ (84/288), and 20 of those 84-patients experienced repeatedoperation [rate of re-operation was $23.8 \%$ (20/84)], while the other 64-patients experienced conservational managements. The rate of recurrence of the surgery group was $21.3 \%$ (26/122), and the median non-recurrence period was 19.3-mths. Also, the same study of Mu et al., [16] reported that the rate of recurrence of the conservational managing group was $34.9 \%$ (58/166), and the median nonrecurrence period was 33.1-mths. The changes in the rate of recurrence among the study groups have been taken in to consideration as significant ( $p$-value $=.010$ ).

Kabbash et al., [17] reported that as regard to recurrence, after following-up for 6-mths it occurred in 4 patients $(14 \%)$ in group A with conservative treatment and 2 patients (9\%) in group B (surgical treatment) with nonsignificant change among the two study groups.

Further more, in therate of recurrent of the simple ASBO-group was $28.6 \%$ (19/72), and the median non-recurrence period was 12.2-mths. The rate of recurrence of the strangulating obstructions group was $37.5 \%$ (3/8), and the median nonrecurrence period was 11.5 -mths. The changesamong the studied groups weren't counted as significant $(p$-value $=0.241)$.

$\mathrm{Mu}$ et al., [16] reported that the rate of recurrent of the simple ASBO-group was 28.6\% (72/251), and the median non-recurrence period was 32.2- 
mths. Therate of recurrence of the strangulating obstructions group was $32.4 \%$ (12/37), and the median non-recurrence period was 11.5 -mths. The changes among the studied groups were not counted as significant ( $p$-value $=0.186)$, the median nonrecurrence periods of men and women cases were 31.6-mths and 31.2-mths, correspondingly. A nonsignificant change was found among the nonrecurrence periods of man and women cases ( $p$-value $=0.899$ ). The median non-recurrence periods among cases ages.

The current work showed that ASBO-cases who experienced operative management have a decreased rate of recurrence in comparison with those of nonoperative group. Generally, operative management reduced the ASBO recurrence. The consequences are agreed with preceding reports of Fevang et al., [22]; Yang et al., [23] ; Isaksson et al., [24].

\section{Limitations:}

The current work has some limitations: $1^{\text {st }}$, this is a retrospective investigation, likenon-complete or missed data attained from chart reviews. For example, some inflammatory bio-markers weren't commonly employed in our department like CRP, procalcitonin, erythrocyte sedimentations and neutrophil-to-lymphocyte ratio. $2 \mathrm{nd}$, it is a monocentric study, so it needs additional validations. Additional large size multi-centric investigations are desired.

In conclusion, the treatment of ASBO is highly based on surgeon decision, involving decision on how long to try conservative intervention and if or not to employ a laparoscopic or open method if operation is desired, this work approves that two classical clinical factors and two CT findings are the clinical features accompanying with intestinal strangulations of ASBO, surgeries can lessening ASBO rate of recurrence.

\section{References}

1- SCOTT J.W., OLUFAJO O.A., BRAT G.A., ROSE J.A., ZOGG C.K., HAIDER A.H., et al.: Use of national burden to define operative emergency general surgery. JAMA Surg., 151 (6): e160480, 2016.

2- TEN BROEK R.P., ISSA Y., VAN SANTBRINK E.J., BOUVY N.D., KRUITWAGEN R.F., JEEKEL J., et al.: Burden of adhesions in abdominal and pelvic surgery: Systematic review and met-analysis. BMJ, 347, 2013.

3- STRIK C., STOMMEL M.W.J., SCHIPPER L.J., VAN GOOR H. and TEN BROEK R.P.G.: Long-term impact of adhesions on bowel obstruction. Surgery, 159: 13519, 2016.

4- LOFTUS T., MOORE F., VAN ZANT E., BALA T., BRAKENRIDGE S., CROFT C., et al.: A protocol for the management of adhesive small bowel obstruction. The Journal of Trauma and Acute Care Surgery, 78 (1): 13, 2015.

5- PARIKH J.A., KO C.Y., MAGGARD M.A., ZINGMOND D.S.: What is the rate of small bowel obstruction after colectomy? Am. Surg., 74 (10): 1001-5, 2008.

6- PRICOLO V.E. and CURLEY F.: CT scan findings do not predict outcome of nonoperative management in small bowel obstruction: Retrospective analysis of 108 consecutive patients. Int. J. Surg., 27: 88-91, 2016.

7- BILDERBACK P.A., MASSMAN III J.D., SMITH R.K., La SELVA D. and HELTON W.S.: Small bowel obstruction is a surgical disorder: Patients with adhesive small bowel obstruction requiring operation have more costeffective care when admitted to a surgical service. Journal of the American College of Surgeons, 221 (1): 7-13, 2015.

8- Di SAVERIO S., COCCOLINI F., GALATI M., SMERIERI N., BIFFL W.L., ANSALONI L., et al.: Bologna guidelines for diagnosis and management of adhesive small bowel obstruction (ASBO): 2013 update of the evidence-based guidelines from the world society of emergency surgery ASBO working group. World Journal of Emergency Surgery, 8 (1): 1-4, 2013.

9- TEN BROEK R.P., KRIELEN P., Di SAVERIO S., COCCOLINI F, BIFFL W.L., ANSALONI L., et al.: Bologna guidelines for diagnosis and management of adhesive small bowel obstruction (ASBO): 2017 update of the evidence-based guidelines from the world society of emergency surgery ASBO working group. World Journal of Emergency Surgery, 13 (1): 1-3, 2018.

10- THORNBLADE L.W., VERDIAL F.C., BARTEK M.A., FLUM D.R. and DAVIDSON G.H.: The safety of expectant management for adhesive small bowel obstruction: A systematic review. Journal of Gastro-intestinal Surgery, 23 (4): 846-59, 2019.

11- TEN BROEK R.P.G., ISSA Y., VAN SANTBRINK E.J.P., BOUVY N.D., KRUITWAGEN R.F.P.M., JEEKEL J., et al.: Burden of adhesions in abdominal and pelvic surgery: Systematic review and met-analysis. BMJ, 347: f5588, 2013.

12- YAHAGI M., ISHII Y., OCHIAI H., SAKO H, MAEDA H., TAKEMURA Y., OKA T., SOUTOME K., KAMIYA N. and WATANABE M.: SurgUsefulness of laparoscopic surgery and preoperative examinations for chronic recurrent small bowel obstruction, Today, May, 51 (5): 807813. doi: 10.1007/s00595-020-02197-y. Epub 2021 Jan 10. PMID: 33423108, 2021

13- ISAKSSON K., MONTGOMERY A., MOBERG A.C., et al.: Long-term following-up for adhesive small bowel obstruction after open versus laparoscopic surgery for suspected appendicitis. Ann. Surg., 259: 1173-7, 2014.

14- LEE H., KIM I.K. and JU M.K.: Which patients with intestinal obstruction need surgery? The delta neutrophil index as an early predictive marker. Ann. Surg. Treat. Res., 93: 272-6, 2017.

15-Di SAVERIO S., CATENA F., ANSALONI L., GAVIOLI M., VALENTINO M. and PINNA A.D.: Water-soluble contrast medium (gastrografin) value in adhesive small intestine obstruction (ASIO): A prospective, randomized, controlled, clinical trial, World J. Surg., Oct. 32 (10): 2293-304. doi: 10.1007/s00268-008-9694-6, 2008. 
16- MU J.F., QUAN WANG, SHI-DONG WANG, CHUANWANG, JIA-XING SONG, JING JIANG and XUE-YUAN CAO: Clinical factors associated with intestinal strangulating obstruction and recurrence in adhesive small bowel obstruction A retrospective study of 288 cases, Medicine, 97: 34, 2018.

17-KABBASH M.M., ABD EL-AAL ALI SALEEM, OSAMA ABDALLAH ABDEL RHEEM and MOHAMMED ABDEL RAOUF ADLY ABD EL-RAHMAN: Surgical Intervention in Adhesive Intestinal Obstruction, The Egyptian Journal of Hospital Medicine (October) Vol. 77 (6), Page 5954-5957 5954 Received:24/08/2019 Accepted:24/09/2019, 2019.

18- WILLIAMS S.B., GREENSPON J., YOUNG H.A., et al.: Small bowel obstruction: Conservative vs. surgical management. Dis. Colon. Rectum., 48: 1140-6, 2005.

19-BOUASSIDA M., LAAMIRI G., ZRIBI S. et al.: Predicting Intestinal Ischaemia in Patients with Adhesive Small Bowel Obstruction: A Simple Score. World J. Surg., 44, 1444-1449. https://doi.org/10.1007/s00268-020-053776,2020 .
20- MATSUSHIMA K., INABA K., DOLLBAUM R., et al.: High-density free fluid on computed tomography: A predictor of surgical intervention in patients with adhesive small bowel obstruction. Gastro-intestinal Surg., 20: 18616, 2016.

21- LORENTZEN L., ØINES M.N., OMA E., et al.: Recurrence after operative treatment of adhesive small-bowel obstruction. J. Gastrointest Surg., 13: 329-34, 2017.

22- FEVANG B.T., FEVANG J., LIE S.A., et al.: Long-term prognosis after operation for adhesive small bowel obstruction. Ann. Surg., 240: 193-201, 2004.

23- YANG K.M., YU C.S., LEE J.L., et al.: The long-term outcomes of recurrent adhesive small bowel obstruction after colorectal cancersurgery favor surgical management. Medicine (Baltimore), 96: e8316, 2017.

24- ISAKSSON K., MONTGOMERY A., MOBERG A.C., et al.: Long-term following-up for adhesive small bowel obstruction after open versus laparoscopic surgery for suspected appendicitis. Ann. Surg., 259: 1173-7, 2014.

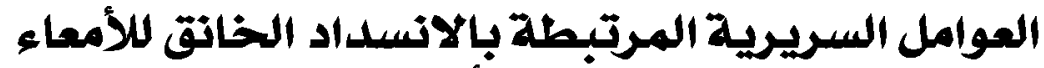

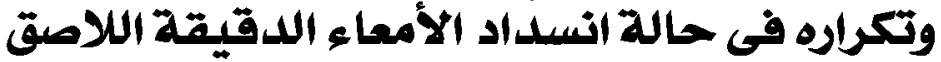

$$
\begin{aligned}
& \text { انسداد الأمعاء الدقيقة اللاصق من أحد أهم الأسباب الرئيسية للطوارئ الجراحية وخاصة فى حالات الطوارئ الجراحية التى تحتاج إلى } \\
& \text { إجراءات طارئة. }
\end{aligned}
$$

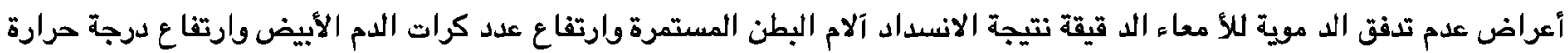

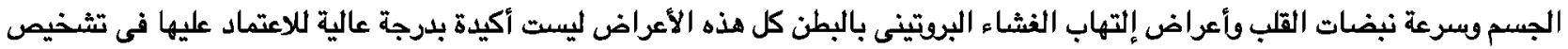

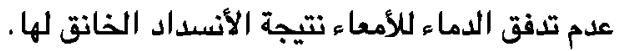

$$
\begin{aligned}
& \text { انسداد الأمعاء الدقيقة الحاد يؤدى إلى أخرار كبيرة بالمرضى التى تستوجب الإقامة فى المستثفى ثمانية أيام في المتوبط ومعدل وفيات }
\end{aligned}
$$

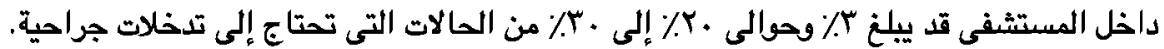

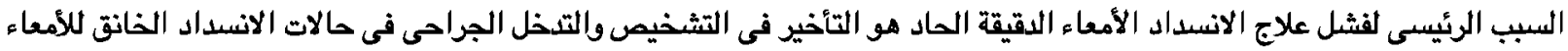

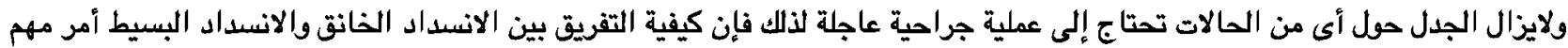

$$
\text { يهدف هذا العمل إلى تقيّم العوامل السريرية المرتبطة بالانسداد الخانق وعوامل الخطر مع معدل تكرار الانسداد الأمعاء الدقيقة الحاد. }
$$

